\title{
Environmental Control of the Respiratory System in the Dimorphic Fungus Mucor rouxii
}

\author{
By CARMEN CANO-CANCHOLA, ${ }^{1}$ EDGARDO ESCAMILLA ${ }^{2}$ AND \\ JOSÉ RUIZ-HERRERA ${ }^{1,3 * \dagger}$ \\ ${ }^{1}$ Facultad de Quimica, Universidad de Guanajuato, Apartado Postal 187, Guanajuato 36000 , \\ Gto., Mexico \\ ${ }^{2}$ Instituto de Fisiologia Celular, Universidad Autonoma de Mexico, Apartado Postal 70-242, \\ 04510 Mexico, $D F$ \\ ${ }^{3}$ Departamento de Genetica y Biologia Molecular, CINVESTAV del IPN, Mexico
}

(Received 28 June 1988)

\begin{abstract}
Spores of Mucor rouxii had low levels of respiratory activity partially sensitive to cyanide and salicylhydroxamic acid (SHAM). They contained a full set of cytochromes but in low concentrations, especially cytochromes $a a_{3}$. Aerobic growth induced a rapid increase in respiratory activity resistant to SHAM but fully sensitive to cyanide, and in the levels of cytochromes, mainly cytochromes $a a_{3}$. These processes were subject to catabolite repression. Incubation under anaerobic conditions, independent of cell morphology, favoured the persistence of SHAM-sensitive respiration, and the maintenance of low levels of $b$ and $c$ cytochromes. No cytochromes $a a_{3}$ were formed under these conditions. CO-difference spectra suggested the presence of cytochrome $o$ in higher levels in aerobic than in anaerobic cells.
\end{abstract}

\section{INTRODUCTION}

Several Mucor species are characterized by their dimorphism, i.e. they are able to grow as mycelium or as a yeast-like form according to the prevailing growth conditions, notably $\mathrm{O}_{2}$ tension and the type and concentration of the carbon source (see reviews by Bartnicki-Garcia, 1963; Sypherd et al., 1978; Inderlied et al., 1985; Ruiz-Herrera, 1985). In general, an anaerobic environment and high concentrations of fermentable carbon sources are associated with yeastlike growth, whereas mycelial growth requires aerobiosis and low concentrations of fermentable or non-fermentable carbon sources.

Storck \& Morril (1971) isolated a respiratory mutant of Mucor bacilliformis which lacked both $b$ and $a$ cytochromes, and which failed to grow as mycelium under aerobic conditions. We have isolated a significant number of yeast monomorphic mutants from $M$. bacilliformis which are unable to grow on non-fermentable carbon sources. These mutants exhibit cyanide-resistant respiration and alterations in their cytochrome pattern (Ruiz-Herrera et al., 1983). Other observations also link mitochondrial development to morphogenesis in Mucor species. Rogers et al. (1974) observed that a reduction in the oxygen tension led to the disappearance of the cytochrome $b$ band from Mucor genevensis, concomitant with the development of yeast-like morphology. Addition of chloramphenicol favoured the yeast-like form in $M$. rouxii (Zorzopolus et al., 1973), but not in $M$. genevensis (Rogers et al., 1974). In both organisms the drug inhibited the expression of cyanide-resistant respiration.

Unfortunately, there are no systematic studies of the cytochrome composition of Mucor species grown under different conditions, and how this is related to the respiratory capacity of

† Correspondence should be sent to the Universidad de Guanajuato address.

Abbreviation: SHAM, salicylhydroxamic acid. 
this fungus. We have examined the cytochrome patterns and the development of respiratory capacity of $M$. rouxii during spore germination and outgrowth as either hyphae or yeast-like cells in order to examine their possible relationships with fungal morphology. Some comparative data on $M$. bacilliformis are also reported.

\section{METHODS}

Strains. Mucor rouxii IM 80 (ATCC 24905) and Mucor bacilliformis NRRL 2346 (ATCC 12830) were used. Media and growth conditions. Strains were maintained on slants of YPG medium (Bartnicki-Garcia \& Nickerson, 1962). Spores were obtained from 4-d-old ( $M$. rouxii), or 7-d-old ( $M$. bacilliformis) aerobic cultures grown at $28^{\circ} \mathrm{C}$ ( $M$. rouxii) or $24^{\circ} \mathrm{C}(M$. bacilliformis) in Roux bottles containing solid YPG medium. Spores were harvested with sterile distilled water, washed twice by low-speed centrifugation, resuspended in sterile distilled water and counted with a haemocytometer. When respiration or cytochrome spectra of ungerminated spores were measured, spores were harvested with a solution containing $100 \mu \mathrm{g}$ cycloheximide $\mathrm{ml}^{-1}$ and $200 \mu \mathrm{g}$ chloramphenicol $\mathrm{ml}^{-1}$, and washed and resuspended in a solution of the same composition. Freshly harvested spores $\left(5 \times 10^{5} \mathrm{ml}^{-1}\right)$ were inoculated in $1200 \mathrm{ml}$ of the defined medium described by Bartnicki-Garcia \& Nickerson (1962) with casein hydrolysate and different carbon sources, contained in 4 litre Erlenmeyer flasks, and incubated at $28^{\circ} \mathrm{C}\left(M\right.$. rouxii) or $24^{\circ} \mathrm{C}$ (M. bacilliformis) either aerobically or anaerobically. Aerobiosis was provided by sparging the cultures with air; anaerobiosis was provided by sparging with a mixture of $\mathrm{N}_{2} / \mathrm{CO}_{2}$ $(70: 30, v / v)$ or with $N_{2}$ alone. In the latter case, the $N_{2}$ was passed through a stainless steel tube containing copper filings heated at $500^{\circ} \mathrm{C}$. The gas was cooled by sparging in a water-trap maintained on ice, and passed through $50 \mathrm{ml}$ of a solution containing $0.025 \mathrm{M}$-methyl viologen and $0.5 \mathrm{mg} \mathrm{Na} \mathrm{S}_{2} \mathrm{O}_{4} \mathrm{ml}^{-1}$, in order to detect any contamination with $\mathrm{O}_{2}$. Results from experiments in which the methyl viologen became oxidized (colourless), were discarded. Unless otherwise indicated $M$. rouxii was grown aerobically for $7-9 \mathrm{~h}$ and anaerobically for $13-$ $20 \mathrm{~h}$, and $M$. bacilliformis was grown aerobically for $13-14 \mathrm{~h}$ and anaerobically for $18-20 \mathrm{~h}$.

Cell harvest and determination of respiratory activity. Cells were harvested by centrifugation and resuspended in one-tenth their volume of fresh medium. Respiration was measured with an oxygen electrode (YSI) in a $2 \cdot 0 \mathrm{ml}$ plastic chamber maintained at 25 or $30^{\circ} \mathrm{C}$ for $M$. bacilliformis or $M$. rouxii respectively. Respiratory activity was calculated as $\mu \mathrm{O}_{2}$ consumed per $10^{7}$ cells or per mg protein per min. KCN (1.0 mM) or SHAM (1.23 mM) were tested as inhibitors of respiratory activity.

Cytochrome analysis. Cells were harvested by centrifugation and washed twice with a solution containing $100 \mu \mathrm{g}$ cycloheximide $\mathrm{ml}^{-1}$ and $200 \mu \mathrm{g}$ chloramphenicol ml-1. The cells were finally resuspended in $50 \mathrm{mM}-\mathrm{Tris} / \mathrm{HCl}$, pH 7.4, containing $5 \mathrm{mM}-\mathrm{CaCl}_{2}$ and $5 \mathrm{mM}-\mathrm{MgCl}_{2}$ (TCM buffer), and broken for $4 \mathrm{~min}$ (for $30 \mathrm{~s}$ periods) in a Braun homogenizer. Extracts were centrifuged at $1100 \mathrm{~g}$ for $5 \mathrm{~min}$ to remove whole cells and cell walls, and the supernatant was centrifuged in a $70 \mathrm{Ti} \mathrm{Beckman}$ rotor at $165000 \mathrm{~g}\left(r_{\mathrm{av}}\right)$ for $50 \mathrm{~min}$ to sediment the mixedmembrane fraction; this was resuspended in TCM buffer containing $50 \%(\mathrm{v} / \mathrm{v})$ glycerol and kept at $-70{ }^{\circ} \mathrm{C}$ until used.

Difference spectra (reduced minus oxidized) were measured at either room temperature $(1.0 \mathrm{~cm}$ path-length cuvettes) or at $70 \mathrm{~K}$ ( $2.0 \mathrm{~mm}$ path-length cuvettes) in a SLM-Aminco Midan II spectrophotometer. Samples were oxidized by flushing with air or by addition of ammonium persulphate, or reduced with sodium hydrosulphite. To obtain the CO-difference spectra of dithionite-reduced samples, $\mathrm{CO}$ was sparged through the samples for about $3 \mathrm{~min}$ before the spectra were recorded at room temperature. A slit-width of $2.0 \mathrm{~nm}$ was used in all experiments.

Quantitative determination of cytochromes was done as described by Escamilla \& Benito (1984). Since the amount of cytochromes in ungerminated spores was too low to be measured accurately in spectra obtained at room temperature, their relative amount was measured as follows: photocopies of spectra at liquid-nitrogen temperature were obtained, and basal lines were drawn between minima of the bands of the cytochrome peaks, which were cut out and weighed. Specific activities and cytochrome concentrations are based on the amount of protein present in the mixed-membrane fraction.

Protein determination. This was done by the Lowry method.

\section{RESULTS}

\section{Development of respiratory capacity during germination of sporangiospores}

Respiratory activity of ungerminated sporangiospores from both $M$. rouxii and $M$. bacilliformis was very low and partially sensitive to cyanide and SHAM. After incubation in an appropriate medium under aerobic conditions, respiratory activity remained relatively constant and equally sensitive to SHAM for some time, then it increased exponentially, and simultaneously became completely sensitive to cyanide, whereas SHAM sensitivity 


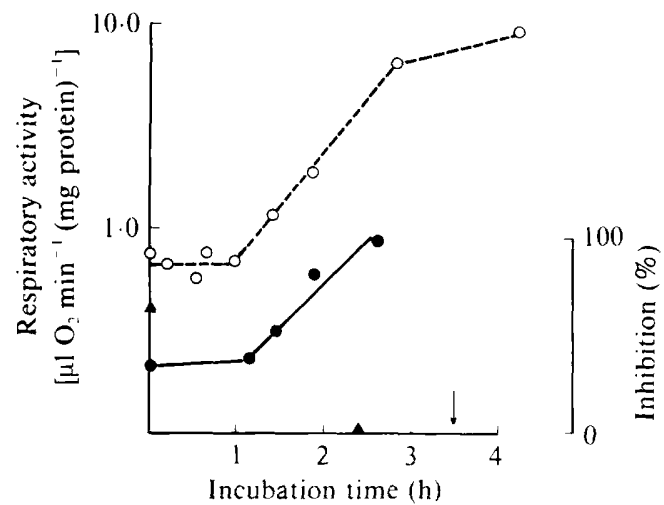

Fig. 1. Development of respiratory activity and sensitivity to cyanide during germination of $M$. rouxii sporangiospores. Spores were incubated aerobically as described in Methods. At various times samples were recovered and respiratory activity was measured $(O)$. Sensitivity of respiration to cyanide (O) or SHAM (A) was determined. The arrow indicates the time when the first germ tubes were observed.

Table 1. Effect of chloramphenicol and cycloheximide on the development of respiratory activity in $M$. rouxii

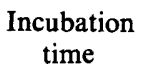

(h)

0

5

5

5

5
Protein synthesis inhibitor

None
None
Chloramphenicol $\left(200 \mu \mathrm{g} \mathrm{m}^{-1}\right)$
Cycloheximide $\left(100 \mu \mathrm{g} \mathrm{ml}^{-1}\right)$
Chloramphenicol +
cycloheximide

\section{Respiratory}

activity $\left(\mu \mathrm{l} \mathrm{O}_{2}\right.$ per min per $10^{7}$ spores)

0.36
1.13
0.97
0.39
0.11

$1 \cdot 13$

0.97

$0 \cdot 11$

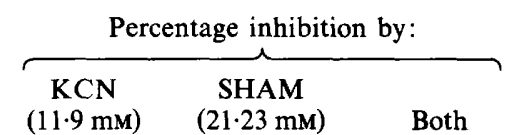

$(11.9 \mathrm{mM}) \quad(21.23 \mathrm{mM}) \quad$ Both

8
100
86
100
82

100

100

100

100

100

$\begin{array}{rl}33 & 100 \\ 0 & 100 \\ 32 & 100 \\ 32 & 100 \\ 41 & 100\end{array}$

disappeared. Fig. 1 shows data for $M$. rouxii. The behaviour of $M$. bacilliformis was similar, but the process was slower (not shown). Full development of cyanide-sensitive respiration preceded germ-tube emergence. $M$. bacilliformis spores incubated at $30^{\circ} \mathrm{C}$ can go through the first stages of germination, but do not produce germ tubes (Storck \& Morril, 1977). Under these conditions, however, full cyanide-sensitive respiration was developed.

We determined the effect of inhibitors of protein synthesis on the development of respiratory activity in sporangiospores from both $M$. rouxii and $M$. bacilliformis incubated under aerobic conditions. In the presence of chloramphenicol, SHAM-sensitive respiration was not completely abolished. Cycloheximide inhibited both spore germination and increase in respiratory activity, but respiration became more sensitive to cyanide than to SHAM. In the presence of both chloramphenicol and cycloheximide, respiratory activity decreased, but sensitivity to SHAM underwent the same changes observed with either of the above (Table 1).

\section{Changes in cytochrome pattern during sporangiospore germination}

Sporangiospores of $M$. rouxii isolated in the cold and in the presence of both chloramphenicol and cycloheximide had a cytochrome spectrum indicative of the presence of cytochromes $b, c$ and $a a_{3}$. However the relative amount of cytochromes $a a_{3}$ compared to the other cytochromes was very low (Table 2). After aerobic incubation in growth medium, cytochrome concentration (based on cell protein) increased rapidly. The most noticeable increase was of cytochromes $a a_{3}$ relative to cytochromes $c$ and $b$ (Table 2). 
Table 2. Cytochrome development during spore germination and outgrowth under aerobic conditions

Incubation
time

(h)

0

4

5

$\quad$ Stage
Sporangiospores
Swollen spores
Germlings

\begin{tabular}{|c|c|c|}
\hline \multicolumn{3}{|c|}{ Cytochrome concentration* } \\
\hline$c$ & $b$ & $a a_{3}$ \\
\hline $1.48(8 \cdot 7)$ & $0.83(4.9)$ & $0.17(1.0)$ \\
\hline $10.89(2 \cdot 3)$ & $5 \cdot 70(1 \cdot 2)$ & $4.70(1.0)$ \\
\hline $9 \cdot 13(1 \cdot 2)$ & $5.45(0.7)$ & $7.45(1.0)$ \\
\hline
\end{tabular}

* Arbitrary units (see Methods). Numbers in parentheses represent ratios taking the $a a_{3}$ value as $1 \cdot 0$.

Table 3. Respiratory activity of $M$. rouxii cells grown under different conditions

\begin{tabular}{|c|c|c|c|c|c|c|}
\hline \multirow{2}{*}{$\begin{array}{c}\text { Carbon } \\
\text { source and } \\
\text { concentration } \\
(\%, w / v)\end{array}$} & \multirow[b]{2}{*}{$\begin{array}{l}\text { Growth } \\
\text { atmosphere }\end{array}$} & \multirow[b]{2}{*}{ Morphology } & \multirow{2}{*}{$\begin{array}{c}\text { Respiratory } \\
\text { activity } \\
{\left[\mu 1 \mathrm{O}_{2} \mathrm{~min}^{-1}\right.} \\
\left.(\text { mg protein })^{-1}\right]\end{array}$} & \multicolumn{3}{|c|}{ Percentage inhibition by: } \\
\hline & & & & $\begin{array}{l}\mathrm{KCN} \\
(1 \mathrm{mM})\end{array}$ & $\begin{array}{l}\text { SHAM } \\
(1.23 \mathrm{mM})\end{array}$ & Both \\
\hline Glucose $(0 \cdot 5)$ & Air & Mycelium & $42 \cdot 1$ & 100 & 0 & 100 \\
\hline Glucose (2.0) & Air & Mycelium & $31 \cdot 0$ & 100 & 0 & 100 \\
\hline Glucose $(8.0)$ & Air & Mycelium & $19 \cdot 0$ & 65 & 15 & 80 \\
\hline $\begin{array}{l}\text { Glucose }(2 \cdot 0)+ \\
\text { phenethyl } \\
\text { alcohol }(0 \cdot 2)\end{array}$ & Air & Yeast-like & 24.9 & 100 & 0 & 100 \\
\hline Glycerol (2.0) & Air & Mycelium & $93 \cdot 0$ & - & - & - \\
\hline Succinate $(2 \cdot 0)$ & Air & Mycelium & 58.4 & - & - & - \\
\hline Glucose $(0.5)$ & $\mathrm{N}_{2}$ & Mycelium & $13 \cdot 0$ & 59 & 25 & 84 \\
\hline Glucose $(2 \cdot 0)$ & $\mathrm{N}_{2}^{2}$ & Yeast-like & $11 \cdot 0$ & 37 & 42 & 77 \\
\hline Glucose $(2 \cdot 0)$ & $\mathrm{N}_{2} / \mathrm{CO}_{2}$ & Yeast-like & $9 \cdot 8$ & 21 & 73 & 73 \\
\hline
\end{tabular}

\section{Effect of oxygen and carbon source on development of respiratory activity}

Sporangiospores of $M$. rouxii were incubated in growth medium supplemented with various carbon sources. Cells were harvested and their respiratory activity was measured. Results (Table 3 ) showed that under aerobic conditions, the greater the amount of glucose present in the growth medium, the less the specific respiratory activity. At low concentrations of glucose $(0.5$ and $2 \%)$, respiratory activity was completely resistant to SHAM and sensitive to cyanide. The same results were obtained even when phenethyl alcohol was added to the culture medium to force the development of yeast-like forms under aerobic conditions (Terenzi \& Storck, 1969). At high glucose concentrations $(8 \%)$, respiration was partially sensitive to cyanide, SHAM, and interestingly, to both, indicating the appearance of a third $\mathrm{O}_{2}$-consuming pathway. As originally described by Bartnicki-Garcia (1963), the yeast-like form was obtained when the medium was sparged with a mixture of $\mathrm{N}_{2} / \mathrm{CO}_{2}$, or with $\mathrm{N}_{2}$ alone when the glucose concentration was high, whereas sparging with $\mathrm{N}_{2}$ in the presence of $0.5 \%$ glucose induced the formation of germlings. In all cases, respiratory activity of these anaerobically grown cells was very low and partially sensitive to cyanide, SHAM or to both, although suggestive quantitative differences were observed (Table 3). Aerobic growth in the presence of non-fermentable carbon sources gave rise to the highest specific respiratory activity (Table 3 ).

\section{Effect of oxygen and carbon source on the development of different cytochrome systems}

Cells grown under aerobic conditions contained cytochromes $c, b$ and $a a_{3}$, but their relative concentrations were influenced by the nature and concentration of the carbon source (Table 4). As observed for respiratory activity, excess glucose produced a decrease in the concentration of cytochromes. Use of non-fermentable carbon sources, such as glycerol or succinate, gave rise to the highest concentrations of cytochromes. Addition of phenethyl alcohol to a glucose- 
Table 4. Cytochrome concentration in $M$. rouxii cells grown under aerobic conditions

\begin{tabular}{|c|c|c|c|c|c|c|}
\hline \multirow{2}{*}{$\begin{array}{c}\text { Carbon } \\
\text { source and } \\
\text { concentration } \\
(\%, w / v)\end{array}$} & \multirow[b]{2}{*}{ Morphology } & \multicolumn{5}{|c|}{$\begin{array}{c}\text { Cytochrome concentration } \\
\left.\text { [pmol cytochrome (mg protein })^{-1}\right]\end{array}$} \\
\hline & & $c$ & $b$ & $a a_{3}$ & $a_{3}-\mathrm{CO}^{*}$ & $o-\mathrm{CO}^{*}$ \\
\hline Glucose $(0.5)$ & Mycelium & $89 \cdot 0$ & $122 \cdot 0$ & $27 \cdot 5$ & $32 \cdot 0$ & 52.0 \\
\hline Glucose $(2 \cdot 0)$ & Mycelium & $17 \cdot 2$ & $46 \cdot 1$ & $5 \cdot 3$ & $17 \cdot 9$ & $10 \cdot 8$ \\
\hline Glucose $(8 \cdot 0)$ & Mycelium & $17 \cdot 3$ & $23 \cdot 0$ & $4 \cdot 5$ & $4 \cdot 0$ & $13 \cdot 0$ \\
\hline $\begin{array}{l}\text { Glucose }(2 \cdot 0)+ \\
\text { phenethyl } \\
\text { alcohol }(0 \cdot 2)\end{array}$ & Yeast-like & $20 \cdot 0$ & $57 \cdot 0$ & $0 \cdot 1$ & $0 \cdot 1$ & $47 \cdot 0$ \\
\hline Glycerol $(2 \cdot 0)$ & Mycelium & $171 \cdot 0$ & $132 \cdot 0$ & $49 \cdot 0$ & $99 \cdot 0$ & $144 \cdot 0$ \\
\hline
\end{tabular}

Table 5. Cytochrome concentrations in $M$. rouxii cells grown under anaerobic conditions

\begin{tabular}{|c|c|c|c|c|c|c|c|}
\hline \multirow{2}{*}{$\begin{array}{c}\text { Carbon } \\
\text { source and } \\
\text { concentration }\end{array}$} & \multirow{2}{*}{$\begin{array}{c}\text { Growth } \\
\text { atmosphere }\end{array}$} & \multirow[b]{2}{*}{ Morphology } & \multicolumn{5}{|c|}{$\begin{array}{l}\text { Cytochrome concentration } \\
{\left[\mathrm{pmol}(\mathrm{mg} \text { protein })^{-1}\right]}\end{array}$} \\
\hline & & & $c$ & $b$ & $a a_{3}$ & $a_{3}-\mathrm{CO}^{*}$ & $o-\mathrm{CO}^{*}$ \\
\hline Glucose $(0.5)$ & $\mathrm{N}_{2}$ & Mycelium & $6 \cdot 8$ & $17 \cdot 7$ & ND & ND & 10 \\
\hline Glucose $(2 \cdot 0)$ & & Yeast-like & $2 \cdot 6$ & $9 \cdot 2$ & ND & ND & 15 \\
\hline Glucose $(2 \cdot 0)$ & $\mathrm{N}_{2} / \mathrm{CO}_{2}$ & Yeast-like & $2 \cdot 2$ & $7 \cdot 6$ & ND & ND & 20 \\
\hline
\end{tabular}

containing medium induced yeast-like development, and decreased significantly the levels of cytochromes $a a_{3}$, but not those of cytochromes $c$ and $b$.

Cells grown under anaerobic conditions contained no cytochromes $a a_{3}$ whatever their morphology (yeasts or mycelium). Levels of $c$ and $b$, but not of $o$ cytochromes (see below) were affected by the concentration of glucose and the presence of $\mathrm{CO}_{2}$ (Table 5). In general, levels of cytochromes $c$ and $b$ were very low compared to those from aerobic cells, but the least affected was cytochrome $b$ which was predominant in spectra of anaerobic cells.

Cytochrome $o$ deserves a special mention. This terminal oxidase, originally described in bacteria (see Smith, 1961), has since been found in several eukaryotic systems (Kronick \& Hill, 1974; Edwards \& Chance, 1982; Scott et al., 1983), including a yeast (Salmon \& Poole, 1980) and a filamentous fungus (Drabikowska et al., 1974), but had not been previously reported in Zygomycetes. It was tentatively identified in both $M$. rouxii and $M$. bacilliformis by its COdifference spectra (Fig. 2), in cells grown under aerobic or anaerobic conditions. Its role in the respiratory activity of $\mathrm{Mucor}$ remains unknown, but the fact that its concentration was raised by both aerobic growth and non-fermentable carbon sources (or low glucose) suggests that it may play a role as a terminal oxidase.

\section{DISCUSSION}

Our results show the extreme plasticity of the respiratory system from Mucor species, which responds drastically to environmental conditions. Aerobically grown mycelium contains the normal set of cytochromes present in eukaryotic mitochondria and displays cyanide-sensitive respiration, whereas anaerobic cells have low levels of $c$ and $b$ cytochromes, lack cytochromes $a a_{3}$, and their respiration is partially sensitive to cyanide and SHAM. Both aerobic and anaerobic cells also contain cytochrome $o$. The type and quantity of the energy source also affect respiration and cytochrome levels.

Ungerminated sporangiospores have low specific respiratory activities which upon germination increase rapidly. Similar observations have been made in other fungi (Brambl, 


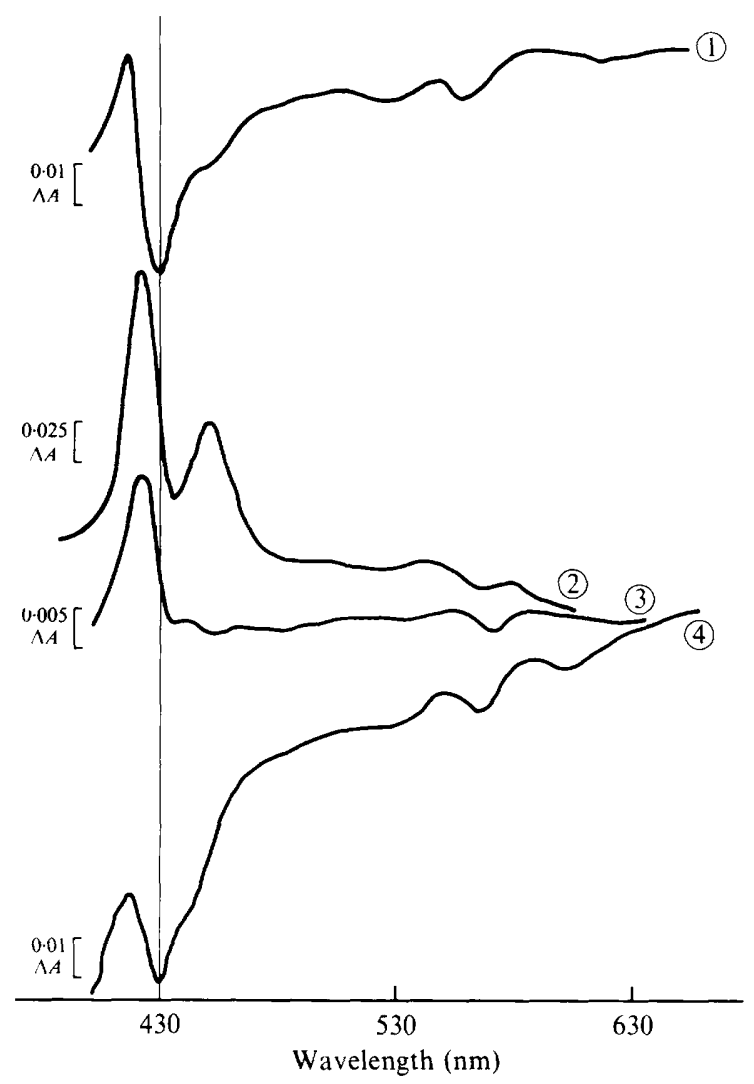

Fig. 2. CO-difference spectra of $M$. rouxii and $M$. bacilliformis cells. $1, M$. rouxii mycelium grown aerobically with $2 \%(\mathrm{w} / \mathrm{v})$ glucose $; 2, M$. rouxii yeasts grown under $\mathrm{N}_{2} / \mathrm{CO}_{2}$ with $2 \%$ glucose; $3, M$. rouxii mycelium grown aerobically with $2 \%(\mathrm{w} / \mathrm{v})$ glycerol; $4, M$. bacilliformis mycelium grown aerobically with $0.5 \%$ glucose.

1975; Kobilinski \& Beattie, 1977; Stade \& Brambl, 1981). Ungerminated sporangiospores of $M$. rouxii contain mitochondria with an apparently normal morphology (Bartnicki-Garcia et al., 1968), but their respiratory pathway is still incompletely organized, since respiration is partially sensitive to cyanide and SHAM. The SHAM-sensitive pathway, which utilizes an alternative route (Lambowitz \& Slayman, 1971), is lost during aerobic, but not anaerobic germination. Whether SHAM-sensitive respiration plays a role during the initial stages of spore germination remains debatable. Thus, SHAM addition inhibits the respiratory activity of Botriodiplodia theobromae spores (Brambl, 1980), but does not affect their germination. On the other hand, SHAM is a potent inhibitor of both the respiratory bypass (Shepherd et al., 1978), and germ-tube formation in Candida albicans blastospores (Shepherd et al., 1980). Mutants of Neurospora crassa affected in cytochrome oxidase exhibit the SHAM-sensitive respiratory pathway (Edwards \& Kwiecienski, 1973; Bertrand \& Werner, 1979). Stade \& Brambl (1981) described that SHAM had only a slight effect on spore germination of these mutants, whereas cyanide inhibited their germination as well as that of wild-type spores. The demonstration that cytochromes $a a_{3}$ were indeed present in the mutant spores led the authors to suggest that the normal cytochrome pathway was indispensable for spore germination. Similar conclusions were reached by Brambl (1975) for B. theobromae.

Inhibition of cytoplasmic protein biosynthesis by cycloheximide blocked development of respiratory activity and growth of the spores. In contrast to previous observations (Zorzopulos et al., 1973), chloramphenicol did not affect either process. It is possible that mitochondrial autogenous proteins are accumulated although not organized in the spores. Their synthesis may 
be required at a later period as has been described for B. theobromae (Brambl, 1975). Sensitivity to SHAM, however, is not lost in the presence of chloramphenicol. In $N$. crassa, Lambowitz \& Slayman (1971) and Edwards \& Rosenberg (1976) have shown that inhibition of mitochondrial protein biosynthesis induces the SHAM-sensitive respiratory pathway suggesting that a mitochondrial gene product is responsible for the regulation of this pathway.

From our results it becomes clear that respiratory activity is not strictly associated with fungal morphogenesis in Mucor. Anaerobic yeast-like cells and hyphae obtained by alterations in the atmospheric environment and carbon source concentration had the same cytochrome composition and their respiration was equally sensitive to SHAM and cyanide. On the other hand, aerobic yeast-like cells obtained by growth in the presence of phenethyl alcohol showed cyanide-sensitive respiration, and contained the same relative amounts of cytochromes $c$ and $b$ but not $a a_{3}$, in agreement with a previous report (Terenzi \& Storck, 1969). The observation that yeast-like mutants are affected in respiratory functions (Storck \& Morrill, 1971; Ruiz-Herrera et al., 1983) suggests that there must exist an association between mitochondrial functions and hyphal growth, but clearly this function is not respiration. Whether the key mitochondrial role is to synthesize ATP, or to compartmentalize specific biosynthetic reactions as suggested by Inderlied et al. (1985), remains to be determined.

This work was carried out with financial support from the Consejo Nacional de Ciencia y Tecnologia, the Direccion General de Investigacion Cientifica y Superacion Academica, SEP and the Fundacion Ricardo J. Zevada, Mexico. We thank Miss Remedios Ramirez for expert technical assistance in some experiments.

\section{REFERENCES}

BARTNICKI-GaRCIA, S. (1963). Symposium on biochemical bases of morphogenesis in fungi. III. Mold-yeast dimorphism of Mucor. Bacteriological Reviews 27, 293-304.

BARTNICKI-GARCIA, S. \& Nickerson, W. J. (1962). Nutrition, growth and morphogenesis of Mucor rouxii. Journal of Bacteriology 84, 841-858.

Bartnicki-Garcia, S., Nelson, N. \& Cota Robles, E. (1968). Electron microscopy of spore germination and cell wall formation in Mucor rouxii. Archiv für Mikrobiologie 63, 242-255.

Bertrand, H. \& Werner, S. (1979). Cytochrome subunits in nuclear and extranuclear cytochrome $a a_{3}$-deficient mutants of Neurospora crassa. European Journal of Biochemistry 98, 9-18.

BRAMBL, R. (1975). Characteristics of developing mitochondrial, genetic and respiratory functions in germinating fungal spores. Biochimica et biophysica acta 396, 175-186.

BRAMBL, R. (1980). Mitochondrial biogenesis during fungal spore germination. Biosynthesis and assembly of cytochrome $c$ oxidase in Botryodiplodia theobromae. Journal of Biological Chemistry 255, 7673-7680.

Drabikowska, A., Kosmakos, F. C. \& Brodie, A. F. (1974). Studies of respiratory components and oxidative phosphorylation in mitochondria of mi-1 Neurospora crassa. Journal of Bacteriology 117, 733740.

Edwards, C. \& Chance, B. (1982). Evidence for the presence of two terminal oxidases in the trypanosomatid Crithidia oncopelti. Journal of General Microbiology 128, 1409-1414.

EDWARDS, D. L. \& KWIECIENSKI, F. (1973). Selection of respiratory mutants of Neurospora crassa. Journal of Bacteriology 114, 164-168.
EDWARDS, D. L. \& Rosenberg, E. (1976). Regulation of cyanide-insensitive respiration in Neurospora. European Journal of Biochemistry 62, 217-221.

EsCAMILla, E. \& Benito, M. C. (1984). Respiratory system of vegetative and sporulating Bacillus cereus. Journal of Bacteriology 160, 473-477.

Inderlied, C. B., Peters, J. \& CihlaR, R. L. (1985). Mucor racemosus. In Fungal Dimorphism, with Emphasis on Fungi Pathogenic for Humans, pp. 337-359. Edited by P. J. Szaniszlo. New York: Plenum Press.

KobILINSKI, L. \& BEATTIE, D. S. (1977). Respiratory competence of Dictyostelium discoideum spores. Journal of Bacteriology 132, 113-117.

KRONICK, P. \& Hill, G. C. (1974). Evidence for the functioning of cytochrome $o$ in the kinetoplastida. Biochimica et biophysica acta 368, 173-180.

Lambowitz, A. M. \& Slayman, C. W. (1971). Cyanide-resistant respiration in Neurospora crassa. Journal of Bacteriology 108, 1087-1096.

Rogers, P. J., Clark-Walker, G. D. \& Stewart, P. R. (1974). Effects of oxygen and glucose on energy metabolism and dimorphism of Mucor genevensis grown in continuous culture : reversibility of yeastmycelium conversion. Journal of Bacteriology 119, 282-293.

Ruiz-Herrera, J. (1985). Dimorphism in Mucor species with emphasis on $M$. rouxii and $M$. bacilliformis. In Fungal Dimorphism, with Emphasis on Fungi Pathogenic for Humans, pp. 361-381. Edited by P. J. Szaniszlo. New York: Plenum Press.

Ruiz-Herrera, J., Ruiz, A. \& Lopez-Romero, E. (1983). Isolation and biochemical analysis of Mucor bacilliformis monomorphic mutants. Journal of Bacteriology 156, 264-272.

SAlmon, I. \& PoOLE, R. K. (1980). The mitochondrial cytochromes of an unusual budding yeast, Sterig- 
matomyces halophilus: spectral characterization exploiting fourth-order finite difference analysis. Journal of General Microbiology 117, 315-326.

ScotT, R. I., Edwards, S. W., Chance, B. \& Lloyd, D. (1983). Terminal oxidase of Crithidia fasciculata. Reaction with carbon monoxide and oxygen at subzero temperatures and photochemical action spectra. Journal of General Microbiology 129, 1983 1989.

ShePherd, M. G., ChI, C. M. \& Sullivan, P. A. (1978). The alternate respiratory pathway of Candida albicans. Archives of Microbiology 116, 61-67.

ShePherd, M. G., Yin, C. Y., RAM, S. P. \& Sullivan, P. A. (1980). Germ tube induction in Candida albicans. Canadian Journal of Microbiology 26, 21-26.

SMITH, L. (1961). Cytochrome systems in aerobic electron transport. In The Bacteria, vol. 2, pp. 365396. Edited by I. C. Gunsalus \& R. Y. Stanier. New York: Academic Press.

Stade, S. \& BRAmbl, R. (1981). Mitochondrial biogenesis during fungal spore germination: respira- tion and cytochrome oxidase in spores of Neurospora crassa. Journal of Bacteriology 147, 757-767.

STORCK, R. \& MORRILL, R. C. (1971). Respiratorydeficient, yeastlike mutant of Mucor. Biochemical Genetics 5, 467-479.

STORCK, R. \& MORRILL, R. C. (1977). Nuclei, nucleic acids and proteins in sporangiospores of Mucor bacilliformis and other Mucor species. Mycologia 49, 1031-1041.

Sypherd, P., Borgia, P. T. \& Paznokas, J. L. (1978). Biochemistry of dimorphism in the fungus Mucor. Advances in Microbial Physiology 18, 67-104.

TERENZI, H. F. \& StORCK, R. (1969). Stimulation of fermentation and yeast-like morphogenesis in Mucor rouxii by phenethyl alcohol. Journal of Bacteriology 97, 1248-1261.

Zorzopulos, J., Jobbagy, A. J. \& Terenzi, H. F. (1973). Effects of ethylendiamine-tetraacetate and chloramphenicol on mitochondrial activity and morphogenesis in Mucor rouxii. Journal of Bacteriology 115, 1198-1204. 